NBER WORKING PAPER SERIES

\title{
COUNTERFEIT OR SUBSTANDARD? ASSESSING PRICE AND NON-PRICE SIGNALS OF DRUG QUALITY
}

\author{
Roger Bate \\ Ginger Zhe Jin \\ Aparna Mathur \\ Working Paper 18073 \\ http://www.nber.org/papers/w18073
NATIONAL BUREAU OF ECONOMIC RESEARCH
1050 Massachusetts Avenue
Cambridge, MA 02138 \\ May 2012
}

This paper previously circulated under the title "Counterfeit or Substandard? The Role of Regulation and Distribution Channel in Drug Safety." The Legatum Institute funded the collection of medicines and testing and a grant from the Social Sciences and Humanities Research Council of Canada provided subsequent funding to cover analysis of survey results. We would also like to thank Andreas Seiter and other participants at the World Bank seminar for their comments and suggestions. All errors are ours. The views expressed herein are those of the authors and do not necessarily reflect the views of the National Bureau of Economic Research.

NBER working papers are circulated for discussion and comment purposes. They have not been peerreviewed or been subject to the review by the NBER Board of Directors that accompanies official NBER publications.

(C) 2012 by Roger Bate, Ginger Zhe Jin, and Aparna Mathur. All rights reserved. Short sections of text, not to exceed two paragraphs, may be quoted without explicit permission provided that full credit, including $(\odot$ notice, is given to the source. 
Counterfeit or Substandard? Assessing Price and Non-Price Signals of Drug Quality

Roger Bate, Ginger Zhe Jin, and Aparna Mathur

NBER Working Paper No. 18073

May 2012, Revised October 2012

JEL No. D8,I15,I18,L15,L51

\begin{abstract}
Pharmaceutical products can be of poor quality either because they contain zero correct active ingredient (referred to as "counterfeit") or because they contain a non-zero but incorrect amount of the right active ingredient (referred to as "substandard"). While both types of poor-quality drugs can be dangerous, they differ in health consequence, price, and potential policy remedies. Assessing basic quality of 1437 samples of Ciprofloxacin from 18 low-to-middle-income countries, we aim to understand how price and non-price signals can help distinguish counterfeits, substandard drugs, and passing drugs.

Following the Global Pharma Health Fund e.V. Minilab ${ }^{\circledR}$ protocol, we find $9.88 \%$ of samples have less than $80 \%$ of the correct active ingredient and $41.5 \%$ of these failures are counterfeits. Both product registration and chain affiliation of retailers are strong indicators of higher probability to pass in the Minilab test and higher retail price. Within quality failures, chain affiliation is more likely to indicate substandard while product registration with local government is more likely to indicate counterfeit. This suggests that registered products are more likely to be targeted by counterfeiters. Furthermore, substandard drugs are priced much lower than comparable generics in the same city but counterfeits offer almost no discount from the targeted genuine version. These findings are consistent with economic theory, and have important implications for both consumers and policy makers.
\end{abstract}

Roger Bate

American Enterprise Institute

1150 Seventeenth Street, NW

Washington DC 20036

rbate@aei.org

Ginger Zhe Jin

University of Maryland

Department of Economics

3105 Tydings Hall

College Park, MD 20742-7211

and NBER

jin@econ.umd.edu
Aparna Mathur

American Enterprise Institute

1150 Seventeenth Street, N.W.

Washington, DC 20036

amathur@aei.org 


\section{Introduction}

Drug safety is a global health problem. According to Pincock $(2003)^{2}$, up to $10 \%$ of the world's pharmaceutical trade $-25 \%$ in developing countries - involves poor quality drugs. The spectrum of poor quality drugs is particularly wide, ranging from a near precise copy of a genuine product to the extreme case of a drug product with none of the correct active ingredient (Newton et al. 2011). ${ }^{3}$

Using the Global Pharma Health Fund e.V. Minilab® test on 1437 samples of Ciprofloxacin, we classify drugs according to its active ingredient only - those with zero correct active ingredient are referred to as "counterfeit", those with some but less than $80 \%$ of correct active ingredient are referred to as "substandard", and the rest are grouped as "passing" although they could still have imperfect quality due to impurity, degradation, etc. ${ }^{4}$

This simple and conservative definition is similar to the definition in Nayyar et al. (2012) but not exactly the same as that of the World Health Organization (WHO). WHO (2010) emphasizes "the intent to deceive" in counterfeits, partly because it is important to prove intent for significant legal sanction against counterfeiters. While selling a drug with zero correct active ingredients clearly misleads buyers, it is extremely difficult to prove intent in practice, especially if the focus is on the intent to infringe trademark rather than the intent to provide effective medicines. As a result, deliberating on intent often diverts attention from products where intent cannot be demonstrated. Partly because of this problem, WHO has been hosting meetings of experts to derive clearer and more practical definition of substandard/spurious/falselylabeled/falsified/counterfeit medical products (WHO 2011). For lack of a new and widely agreed term, we use the old terms but clarify our own definition of counterfeit and substandard drugs.

Our definition focuses on ingredient for three important reasons.

First, both counterfeit and substandard drugs can be dangerous for human health, but their negative effects may differ (Newton et al. 2010). With no correct active ingredients,

\footnotetext{
${ }^{2}$ Pincock (2003) cites these numbers as from the World Health Organization (WHO) but does not give the direct source of reference from WHO. The same numbers are cited in the review paper of Kelesidis et al. (2007).

${ }^{3}$ Between January 1999 and October 2000, the WHO received 46 confidential reports relating to poor quality drugs from 20 countries. About 60 percent of these came from developing countries. The drugs counterfeited included antibiotics, hormones, analgesics, steroids and antihistamines. About 32 percent of these drugs had no active ingredient, 20 percent had incorrect quantities of the active ingredient and 21 percent had the wrong active ingredient. In addition the WHO found that another 8.5 percent had high levels of impurities and contaminants. (http://www.who.int/medicines/services/counterfeit/overview/en/).

${ }^{4}$ As we discuss later, the $80 \%$ cutoff comes from the minilab test, where the test accords a passing value to drugs with more than $80 \%$ active ingredient and a fail to drugs with less than that value.
} 
counterfeits constitute no treatment at all. At the very least, it delays correct treatment and exacerbates conditions being treated; wrong ingredients may even cause additional problems. In either case death may result (Newton et al. 2002). In comparison, for many diseases, substandard drugs may be more beneficial than counterfeits because the correct active ingredient in them could provide partial benefits to patients or full benefits to some patients (especially physically smaller patients - doctors usually prescribe the same dose of antibiotic to all adults regardless of size). However, for drugs prone to resistance, such as those for treating infectious diseases (e.g. antibiotics), consuming some correct active ingredient could be even worse than consuming no active ingredient for patients themselves and the population as a whole, since the strain of the disease they are infected with may become totally resistant to even good quality versions of the substandard drug being taken (Bate et al. forthcoming). A better understanding on the ingredient distinction between counterfeit and substandard drugs will help determine the public health consequence of poor drug quality, and hence help drive public health responses.

Second, the retail price of counterfeit and substandard drugs could differ greatly and therefore generate different tradeoffs between drug quality and drug affordability. As shown in our sample, substandard drugs are priced much lower than comparable generics in the same city but counterfeits offer almost no discount from the targeted genuine version. In the situations where partial treatment is better than no treatment, banning substandard drugs could deny poor patients, who may not be able to access, or afford, better products, from receiving substantial and curative doses of the correct active ingredient.

The third, and probably most important, reason for distinguishing substandard and counterfeit drugs is that combating their spread requires different strategies. For example, in many cases, substandard drugs arise from substandard production by legitimate manufacturers and therefore can be addressed by greater regulatory monitoring, enforcing or increasing standards of manufacturing, and better education of manufacturing staff (Caudron et al. 2008). In contrast, zero-active-ingredient counterfeits are often produced by criminals who have little knowledge in drug manufacturing, hire as few employees as possible, and engage in a "hit and run" strategy. Combatting them often entails enforcing strict criminal laws, unlicensed factory closure, custom investigation, intelligence and police monitoring, case development and then legal prosecution (Newton et al. 2005). 
Regulators are not necessarily the only party fighting against counterfeit and substandard drugs. Legitimate pharmaceutical manufacturers, especially large companies that produce brandname blockbuster drugs, are interested in cracking down on counterfeit medications that infringe on their property rights. According to Transparency Market Research, the health care industry spent 1.2 billion USD in 2012 on just one type of anti-counterfeiting tracking system. ${ }^{5}$ The signing of the Anti-Counterfeiting Trade Agreement in 2011 also shows that governments and pharmaceutical companies are serious about limiting counterfeits in the interest of protecting property rights. ${ }^{6}$ Yet nothing in this agreement or any other piece of international law coordinates the control of other poor-quality medications that could be counterfeit or substandard by our ingredient definition but do not infringe on well-known brands. ${ }^{7}$ While the incentive to protect property rights is understandable, ignoring the other counterfeit and substandard drugs problems could generate serious public health problems and hurt the poor populations that cannot afford brand-name drugs. ${ }^{8}$ It is economically more feasible to differentiate poor quality medicines by ingredient than prove "intent to deceive", and such differentiation can assist national regulators and global actors like WHO to target their efforts more effectively.

Despite the importance of even crudely separating counterfeits from substandard drugs ${ }^{9}$, very few studies distinguish the two by ingredient, and none analyze the price and non-price signals that could help identify passing, counterfeit, and substandard products. To fill in the gap, we acquire 1437 samples of Ciprofloxacin from 18 low-to-middle-income countries, analyze their quality following the Global Pharma Health Fund e.V. Minilab® protocol, and link the test results to local regulations, demographics, and distribution channels. Overall, $9.88 \%$ of samples fail the tests and $41.5 \%$ of the failures are counterfeits.

\footnotetext{
${ }^{5}$ Transparency Market Research, "Global Radio Frequency Identification (RFID) in Healthcare Industry is Expected to Reach USD 3, 351.6 million by 2018: Transparency Market Research," The Sacramento Bee, October 9, 2012, http://www.sacbee.com/2012/10/09/4893925/global-radio-frequency-identification.html.

${ }^{6}$ ACTA has been signed by the United States, UK, Austria, Belgium, Bulgaria, Czech Republic, Denmark, Finland, France, Greece, Hungary, Ireland, Italy, Latvia, Lithuania, Luxemburg, Malta, Poland, Portugal, Romania, Slovenia, Spain, Sweden Mexico, Australia, Canada, South Korea, Japan, New Zealand, Morocco, and Singapore. See Anti Counterfeiting Trade Agreement, http://www.mofa.go.jp/policy/economy/i_property/acta.html.

${ }^{7}$ Medicines Sans Frontieres, "A blank cheque for abuse," 2012, http://www.msfaccess.org/sites/default/files/MSF_assets/Access/Docs/Access_Briefing_ACTABlankCheque_ENG_ 2012.pdf

8 "Crisis of poor quality medicines being used as an excuse to push up prices for poor." Oxfam. Press Release. February 2, 2011. http://www.oxfam.org/en/pressroom/pressrelease/2011-02-02/crisis-poor-quality-medicinesbeing-used-excuse-push-prices-poor

${ }^{9}$ See Kelesidis et al. (2007) and Caudron et al. (2008) for reviews of public health literature on this topic. See USAID (2009) for an example of policy concern on substandard and counterfeit medicines.
} 
Our analysis shows that substandard and counterfeit drugs exhibit statistically significant price differences relative to the genuine drug. Within failures, counterfeits are $\$ 0.36$ more expensive than substandard drugs. More importantly, substandard drugs are priced 30.3\% lower than comparable generics in the same city but counterfeits offer almost no discount relative to the genuine version they aim to mimic. The pooling of counterfeits and passing drugs on price does not allow consumers to distinguish the two based on price only, but the different business strategy of substandard and counterfeit manufacturers suggest that non-price signals might play a complementary role in assessing drug quality.

For example, a more careful look at the data suggests that both regulation and distribution channel have power predicting whether a sample fails the Minilab test. Products that are registered by western regulators or the World Health Organization (WHO) have the highest passing rate $(98.5 \%)$. Products registered with local authorities also have a greater passing rate (93.5\%) than non-registered products $(69.8 \%)$, so are the products sold in chain pharmacies $(98 \%)$ relative to those from non-chain pharmacies $(79.9 \%)$. Consistently, price is much higher for registered products and products from chains. However, neither chain affiliation nor product registration implies good quality for sure. Conditional on failing the Minilab test, we find failures from pharmacy chains are more likely to be substandard, but failures with local registration are more likely to be counterfeit.

The rest of the paper is organized as follows. Section 2 describes the background and data. Section 3 reviews economics and management literature about quality control. Data analysis is presented in Section 4. Section 5 discusses what implications these findings have for both consumers and policy makers.

\section{Background and Data}

While concern about safety is relevant for all prescription and over-the-counter drugs, we choose to focus on one type of prescription drug that was available universally across all Africa and mid-income country cities: ciprofloxacin. Ciprofloxacin (more commonly called Cipro) is a very important antibiotic used to treat numerous bacterial infections, most famously anthrax. ${ }^{10}$

\footnotetext{
${ }^{10}$ Bayer has been marketing products in Africa since 1920. Manufacturing sites are located in Morocco and South Africa. Bayer South Africa Ltd. was established in 1970 and is responsible for business across the Southern Africa sub region (Botswana, Congo, Lesotho, Madagascar, Malawi, Mauritius, Mozambique, Namibia, Réunion, Swaziland, Zambia and Zimbabwe.) Nearly 50 percent of Africa's sales take place in South Africa, but Bayer also
} 
Cipro demand exploded in United States post-9/11, thanks in part to news anchor Tom Brokaw's ringing "in Cipro we trust" endorsement.

German pharmaceutical company Bayer AG first patented Cipro in 1983. The FDA approved the Cipro tablet in 1987, its intravenous solution in $1990,{ }^{11}$ and its use in postexposure inhalational anthrax cases in 2000. ${ }^{12}$ Based on new prescriptions, Cipro was ranked in 1999 the $11^{\text {th }}$ most prescribed drug in the US, and the $20^{\text {th }}$ in total US sales (grossing $\$ 1.04$ billion. ${ }^{13}$ )

Since Bayer's US patent on the drug did not expire until $2003^{14}$, the 2001 anthrax scare significantly boosted its sales. In October of 2001, President Bush announced a deal between the Federal Government and Bayer in which the government purchased 100 million tablets of ciprofloxacin at a reduced price of $\$ 0.95 /$ pill (compared to $\$ 1.77 /$ pill). ${ }^{15}$ This deal was only reached after the Bush Administration had threatened to declare a national emergency, which would have, according to WTO rules on trade-related aspects of intellectual property, allowed the administration to waive the Bayer patent and purchase generics from a different manufacturer. In fact, Deepak Chatterraj, the head of the US division of Ranbaxy Laboratories, was approached by a US senator wondering whether the company would have had the capacity to supply the anti-anthrax drug to the United States. ${ }^{16}$ Canada recognized the Cipro patent prior to $9 / 11$, but chose to override the patent in October of $2001{ }^{17}$

Pharmaceutical companies were eager for Bayer's patent on Cipro to expire, hoping to break into the US market with their low-cost versions. ${ }^{18}$ In 2001, over 78 Indian pharmaceutical companies, among them Ranbaxy, Dr. Reddy's Lab, and Cipla, were producing generic versions of Cipro outside of the US for one-thirtieth of what Bayer charged. ${ }^{19}$ In June of 2003, generic

has affiliates split into three groups: North Africa, West and Central Africa, and East Africa and Southern Africa. Operations of Bayer East Africa Ltd. are based in Nairobi, while Bayer Maghreb S.A., headquartered in Casablanca, Morocco, conducts Bayer's activity in North, West, and Central Africa.

${ }^{11} \mathrm{http} / / / \mathrm{www} . \mathrm{fda} . \mathrm{gov} / \mathrm{ohrms} / \mathrm{dockets/ac/00/backgrd/3632b1a.pdf}$

${ }_{12} \mathrm{http:// \text {cid.oxfordjournals.org/content/39/3/303.full }}$

${ }_{13} \mathrm{http} / / / \mathrm{www}$.prescriptionaccess.org/lawsuitssettlements/past lawsuits? $\mathrm{id}=0010$

14 According to the FDA, Cipro® oral tablets and Cipro® oral suspensions [were] off patent and available generically in 2005. (http://www.fda.gov/ohrms/dockets/ac/05/briefing/2005-

4152b1_03 02_Cipro\%20Use\%20Cleared.pdf ).

${ }^{15} \mathrm{http}: / /$ articles.cnn.com/2001-10-25/health/government.cipro_1_cipro-anthrax-treatment-anthraxantibiotic?_s=PM:HEALTH

$\frac{16}{16} \mathrm{http}: / /$ news.bbc.co.uk/2/hi/business/1613410.stm

${ }_{17}$ http://www.usatoday.com/news/attack/2001/10/19/cipro-canada.htm

${ }^{18}$ www.investor.bayer.com/user upload/1320/

${ }_{19}$ http://www.forbes.com/2001/10/17/1017cipro.html 
Cipro tablets entered the market and sales of Bayer's brand product declined as generic versions comprised $69 \%$ of the total Cipro tablets sold in 2004. However, Cipro remained the popular choice in the fluoroquinolones class, accounting for $41 \%$ of the 33.5 million prescriptions written in 2004, and the prescription volume for the drug increased by 0.2 million from 2003 to $2004 .^{20}$

Sampling Method Given the popularity of Cipro, we acquired samples of tablet Cipro from 22 cities in 18 countries. For any city in our data, samples were procured by covert shoppers in at least two median income areas of the city. The buyers bought from retail pharmacies, ignoring other possible outlets like kiosks and mobile sellers. In particular, a covert shopper was instructed to walk in a retail pharmacy randomly, claim that an adult family member is suffering from a nasty bacterial infection, and request Cipro because a family friend/doctor suggested so. Then the shopper will follow the in-store pharmacist's guidance (if any) to make a purchase. We did not instruct covert shoppers to aim for any particular brand or price range, as doing so could make the pharmacist suspicious of covert shopping and behave differently.

Of all the visited pharmacies, $92 \%$ of them had Cipro, another $8 \%$ or 114 pharmacies either did not sell it or did not have it in stock on day of visit. Only pharmacies with Cipro in stock were recorded. In total, we collected 1437 treatment samples of 121 brands. The 22 cities in our sample included 5 cities in India (Chennai, Delhi, Hyderabad, Kolkata and Mumbai) and 12 cities in Africa (Accra, Addis Ababa, Cairo, Dar Es Salaam, Kampala, Kigali, Lagos, Luanda, Lubumbashi, Lusaka, Maputo, and Nairobi). The remaining 5 cities were in mid-income nations, including Bangkok, Beijing, Istanbul, Moscow and Sao Paolo. The first 185 samples of Cipro were collected prior to 2012 (in previous samplings and already published in the literature ${ }^{21}$ ). Another 1252 are new samples collected and tested in 2012.

The data are not broken down by brands because sample sizes of each brand are too small for any meaningful statistical assessment. Anecdotal observations about which types of products may be more likely to be counterfeited will be made in the discussion section of the paper. However, the country of manufacturing, whether the product is a generic or innovator brand, whether the product is registered with a local authority, whether the product is registered with a foreign country that has stringent standard, and whether it is approved by the WHO is recorded

\footnotetext{
${ }^{20} \mathrm{http}: / /$ www.fda.gov/ohrms/dockets/ac/05/briefing/2005-4152b1 03 02_Cipro\%20Use\%20Cleared.pdf

21 See Bate et al. (2008, 2009a, 2009b, 2010a) and Bate and Hess (2010).
} 
for each product. ${ }^{22}$ About $7 \%$ of our data was innovator brand, in keeping with lack of patent protection for Cipro in every market.

Quality Assessment All medicines were assessed following the Global Pharma Health Fund e.V. Minilab® protocol to identify substandard or counterfeit medicines. The first test is a visual inspection of packaging and pills for correctness. Depending on the drug being analyzed this can be followed by dye tests for presence of active ingredient and a disintegration test for basic solubility, but by far the most important test, and the key test for our sample, is the semiquantitative thin-layer chromatography (TLC) for assessing the presence and relative concentration of active ingredient. All the tests were conducted with the Africa Fighting Malaria Minilab in the United Kingdom within 60 days of purchase.

Minilab tests were run in duplicate, with the generous assumption that the result more consistent with the reference standard Cipro (provided by GPHF) was recorded. Quality control of the Minilab was performed daily prior to testing and consisted of performing TLC on Minilabreference samples for the medicine classes being analyzed. In addition, Minilab reagents were quality control tested using reference samples when a new lot was introduced. The Minilab protocol awards medicines a "pass" for active ingredient (by TLC) if they have $80 \%$ or more of the labeled active ingredient(s).

The visual check is by definition subjective, but all our visual failures turn out to have zero active ingredient in the chromatography test, suggesting that the probability of an incorrect visual assessment is vanishingly low. In some instances, we were able to get immediate and helpful confirmation from companies that suspected products were indeed counterfeit unsurprisingly no company admits to making a substandard product themselves. But for most of the sample, we rely solely on the detected amount of active ingredient to classify them into passing, substandard, or counterfeit. We do not have access to a compendia laboratory to assess all possible problems with medicines, hence some medicines could pass the visual and chromatography tests but still fail potential tests for solubility, permeability, product degradation, trace element contamination and pathogenic contamination. In other words, if a drug fails one of the above simple tests it is definitely poor quality, but if it passes it may be a higher quality, but

\footnotetext{
${ }^{22}$ Whether a product is approved by a stringent regulatory body like the FDA is perfectly collinear with whether the product is of innovator brand.
} 
still far from perfect medicine. In that way our record of poor quality products is conservative, some less obvious poor quality products may be classified as passing in our assessment.

Regulations Counterfeiting can be a low-cost, high-return business, especially if regulations are weak. At present, out of the 191 WHO member states, only 20 percent are known to have well developed drug regulation. ${ }^{23}$ However, having regulations per se is an insufficient deterrent unless there is significant market surveillance, strong enforcement, and sufficient penalties for those who are caught breaking the rules.

For the purpose of this study, we classify regulations in three types: one is ex ante regulation that identifies legitimate manufacturers and legitimate products by examining the manufacturing practice before the products go on the market. This registration process can be done by local or international drug safety authorities. As shown in Oxfam (2011) and Bate et al. (2010b), local drug registration is the most primitive regulation on legitimate drugs but its availability and implementation vary greatly across countries. Using drug registration data collected in Bate et al. (2010a and 2010b), we created a dummy variable equal to one if a drug has been registered in the purchase country at the purchase time.

International authorities also take actions to address drug quality. For example, if a manufacturer in Brazil or India wishes to sell products in Nigeria or China, buyers in these latter countries may want proof of quality that the products achieve high standards, and may not accept registration in India and Brazil as proof. The company can choose to register these products in a western country with a stringent drug regulatory authority to establish quality, but this is expensive, time consuming, and rarely done if the company does not intend on selling in western nations. ${ }^{24}$ To assist such producers, as well as donors that might wish to buy quality generics, the WHO established a prequalification program, where generics producers could at a much lower cost establish higher levels of quality control than regulatory authorities in emerging countries could achieve.

The second type of drug regulation is ex post penalty for counterfeiters. We proxy it by the number of months a person will be sentenced in prison if he is found guilty for counterfeiting drugs. We hand collected minimum and maximum penalty from the latest legal documents we can find in each country. For example, Egyptian IP Law sets down a number of penalties,

\footnotetext{
${ }^{23} \mathrm{http}: / / \mathrm{www}$. who.int/medicines/services/counterfeit/overview/en/index 1.html.

24 In our data, registration with a stringent regulatory authority in a western country is perfectly collinear with whether the drug sample carries an innovator brand.
} 
including prison terms, for persons making or selling counterfeit goods. Monetary penalties range from $\$ 90$ to $\$ 9,000$, and terms of imprisonment range from 2 months to 3 years. Prison terms are mandatory only for repeat offences. ${ }^{25}$ In July 2008, the Indian cabinet approved a bill that increases fines for convicted counterfeiters from USD $\$ 250$ to a minimum of USD $\$ 22,550$ or three times the value of the drugs confiscated. They also increased the jail sentences for those convicted of counterfeiting from 5 years to a minimum of 10 years to life. ${ }^{26}$ To accommodate diverse sentencing guidelines, monetary fines are coded as zero months and death penalty is coded as 360 months (30 years). We use maximum penalty in the data.

It is commonly believed that approval by a western country with stringent standard (referred to as SRA approved) and WHO prequalification, are more stringent than registering locally in a low-to-middle-income purchase country. The relative stringency of SRA approval and WHO prequalification is less clear. Both SRA and WHO use similar inspectors and follow a similar inspection procedure ex ante, but WHO does not do as much (if any) post market surveillance, which is critical to prevent legitimate manufacturers from cutting corners ex post. In this sense, we believe products with SRA approval could be of consistently higher quality than products with WHO prequalification only. If this belief is correct, we expect quality to decrease in the order of SRA approval, WHO prequalified, local registered, and none of the above. The Minilab test should identify some of these quality differences.

The third type of drug regulation focuses on issues other than drug safety, for example the purchase country could issue price ceilings, mandatory retail price, and price guidance. We hand collected these regulations from each country's most recent government documents. Given the wide variety of price regulations, we define a binary variable equal to one if a country has adopted any price regulation on pharmaceuticals in the data collection year and zero otherwise.

Intellectual property protection considerations are less relevant for our sample, because Bayer's patent on Cipro expired in all countries sampled before our data acquisition and most of the drugs in our sample are generic instead of innovator brand. Additionally some of the "brands" actually do not have a brand name, but are just called ciprofloxacin and hence could not breach a trademark. Trademark violations are often the criterion most noticeable in our visual assessment and hence trademarks are often a useful guide for spotting poor quality, In this

Available at: http://www.notofakes.com/Resources/TravelAdvisory/Africa/Egypt/tabid/495/Default.aspx

Available at: http://cdsco.nic.in/Guidelines\%20under\%20new\%20penal\%20provisions.pdf 
sample, all products infringing trademarks turn out to have zero correct active ingredients and therefore satisfy our counterfeit definition, but only a small fraction of the zero-ingredient samples display apparent trademark violation. This discrepancy highlights the importance of checking ingredient in addition to trademark infringements.

Demographics Factors like income and education of consumers will determine the demand and price of drugs. Specifically, we obtain male and female adult literacy rates for ages 15 and over from country-specific UNESCO data from 2009, compiled from censuses and surveys between 1999-2009. For four countries, Brazil, Egypt, Ethiopia and South Africa, UNESCO did not have 2009 figures. In these cases, we relied on the 2009 UNDP Human Development Report (UNDP 2009), which compiles country-specific data from censuses and surveys conducted between 1999 and 2007, also compiled by UNESCO. The literacy rates of these four countries are therefore slightly older than the rest. We take the average of female and male literacy rates as they are highly correlated (correlation coefficient $=0.89$ ).

The year- and city-specific GDP per capita data are denominated in US\$ of purchasing power parity (PPP). They were constructed using the 2008 city GDP estimates by PricewaterhouseCoopers (PWC 2009) and the 2009 and 2010 city population estimates from the 2009 revision of the UN's World Urbanization Prospects Report (UN 2009). We extended the 2008 GDP estimates from 2009 through 2012 using country level GDP growth rates from the International Monetary Fund (IMF). The IMF records GDP growth rates through 2011, and offers projections for 2012. We extended the city population estimates backwards to 2008 and forward to 2010 using the UN report's 2005-2010 average population growth figure. City population estimates for 2011 and 2012 were calculated using the annualized population growth rate using the UN report's 2010 and 2015 estimated population growth figures. For Accra, Maputo, Lubumbashi, Kigali, Kampala, and Lusaka, city-level data was not available and we used country-level GDP per capita from the IMF World Economic Outlook Database as of October 2011 (IMF 2011).

Chain affiliation A pharmacy was considered to be part of a chain if at least two distinct stores with similar layout and under the same retail logo were found in at least two different parts of the same city or multiple cities. For example, there are 57 CFW Shops in at least three parts of Nairobi, Kenya and we sampled from three of them. The largest chain we came across was Apollo Pharmacy, which has over 1,000 shops across India, we sampled from them in three 
Indian cities. The covert shoppers were asked to provide a binary quality assessment of the pharmacy they bought from - taking on board to give an overall assessment whether the pharmacy appeared clean, had temperature control, was well-stocked, and had responsive, intelligent staff. This is obviously a subjective assessment but we consider it useful since a good looking store may direct middle class, more discerning shoppers, to subjectively more attractive and efficient pharmacies.

According to Montague and Lowe (2009), the University of California, San Francisco (UCSF) has studied several countries in Africa and Asia, finding that most countries rely on single outlet stores for pharmaceutical retailing. That being said, they also find recent growth of retail pharmacy chains in South Africa and India, and present limited evidence that such growth has resulted in more pharmacy outlets and lower drug prices.

Price We recorded the original transaction price in local currency, and then translated them into US dollars by exchange rate at the time of purchase. These nominal prices were then deflated using US CPI data. In the tables, all prices are real price in US dollars as of January $2009 .{ }^{27}$ We choose to standardize price by exchange rate instead of PPP because PPP is not available for the most recent (and largest) round of sample collection (February 2012). One price comparison to be shown below examines the price of counterfeit and substandard drugs relative to comparable generics that were acquired from the same city-year and passed the Minilab test. This comparison is robust to any arbitrary yearly fluctuation of PPP. ${ }^{28}$

Source Country of Manufacturing All samples came with at least some packaging hinting at location of production. The vast majority of samples came in blister packages with obvious manufacturing locations written on the secondary (outside/cardboard box) packaging. Where only the blister packs were given, the samples were checked against similar products (the same products usually with different batch numbers), which had secondary packaging. In some instances it was obvious after testing that the product was a fake. For a small subset of these fakes, it was possible (after consulting with the legitimate manufacturer, or local regulator) to discern where the product really came from. For example, Ciprotab, a well-known Indian brand of generic Cipro, is made by VS International of India and marketed by a Nigerian company

\footnotetext{
${ }^{27}$ Deflated according to the US Census Consumer Price Index for all urban consumers, accessed at ftp://ftp.bls.gov/pub/special.requests/cpi/cpiai.txt, on April 27, 2012.

${ }^{28}$ Our regression results are also robust to specifying the GDP data in terms of current exchange rates, rather than PPPs.
} 
called Fidson in Nigeria. We sampled both good quality and counterfeit Ciprotab from Lagos Nigeria; the fake was known by local authorities and by VS International to be made in China.

Figure 1 presents three images. The first one shows the front of a fake package that is virtually indistinguishable from the original, even to trained observers. The second image shows the back of a genuine package, which includes a hologram. The third image shows the back of the fake, without the hologram. Our covert shopper and the pharmacist who sold him the product did not know that the product was supposed to have a hologram. Tests revealed the fake to be a mixture of baby (talcum) powder, glass, and other potentially dangerous substances (Bate 2012). According to Dr. Shah, the managing director of VS International of Mumbai, the fake version has a correct batch number but not when matched with the manufacturing date.

\section{Literature and Predictions}

Before data analysis, it is useful to consider what the economic literature has said about price-quality relationship and the role of regulation and chain affiliation in quality control.

Generally speaking, low and high-quality drugs can co-exist in either a separate or a pooling equilibrium. In a separate equilibrium, consumers can infer the actual product quality from observable signals such as brand, advertising, packaging, price, and retailer attributes. Assuming no one will knowingly pay for a drug with zero active ingredient, counterfeit drugs cannot co-exist with substandard and passing products in a non-deceptive separate equilibrium. ${ }^{29}$ However, this does not imply that consumers must have absolutely no clue about drug quality. Some observable attributes may allow consumers to form different beliefs on the probability of good quality. The substandard may also be separable from good-quality drugs if part of the market is willing to pay for less-than-full active ingredient at a lower price. ${ }^{30} 31$

One potential signal of quality is price (Milgrom and Roberts 1986, Wolinsky 1983). As Wolinsky (1983) pointed out, for price to signal quality in a separate equilibrium, price alone

\footnotetext{
${ }^{29}$ Grossman and Shapiro (1988a) present a non-deceiving separate equilibrium of counterfeits because counterfeits of luxury goods could provide "status" utility, which in turn attracts consumers to pay a less-than-authentic price for counterfeits. This does not apply to the consumption of Cipro.

${ }^{30}$ Grossman and Shapiro (1988b) present a deceptive pooling equilibrium of counterfeits and brand-name products, while generic products are assumed to be distinguishable from both by observable attributes. In their model, pooling effectively implies that counterfeits must infringe the trademark of brand-name products. In our case, if we redefine brand-name products as any products that have more than $80 \%$ of correct active ingredient, mimicking them does not necessarily imply trademark infringement.

${ }^{31}$ By lower price, we mean lower price for the whole package. It is possible that a substandard drug with less active ingredient and a lower package price could effectively sell the drug at a higher price per unit of active ingredient.
} 
cannot be an effective signal of quality unless at least some consumers have a non-price way to distinguish good- and poor quality products. In Bate, Jin and Mathur (2011), we show that price is on average higher for drug samples that pass quality test, but the price distribution of poor quality drugs overlaps greatly with that of good-quality drugs, suggesting that price is at most a weak signal of drug quality.

Another signal for drug quality is manufacturing brand. As shown later, all the innovator brands in our sample are SRA approved. Given the perfect collinearity between the two, we will use SRA approval interchangeably with innovator brand.

Under the belief that SRA approval is more difficult to achieve and maintain than WHO prequalification, and WHO prequalification is more stringent than local product registration, it is natural to expect drug quality (key attributes of which are measured by passing rate of the Minilab test) to follow the same order. However, SRA/WHO/local registration does not automatically imply good quality. Registration processes certify good manufacturing practice and product quality at the time of registration. SRAs do considerable post marketing surveillance as well, while other regulators do this to a limited extent. But even so, registered products can be counterfeited, and even legitimate manufacturers may be tempted to produce poor quality products, unless there is some chance that the true quality will be revealed and the responsible party will face sufficient penalty.

A potential source of such information are consumer reports of drug experience unfortunately, consumer experience is often noisy and does not link treatment failure to poor drug quality for sure. ${ }^{32}$ A second source of information may come from regulator surveillance, for example, regulators can randomly test products on the market, acknowledge high-quality manufacturers, and penalize those that produce poor quality drugs. This route requires significant financial resources, which are usually lacking in developing countries. ${ }^{33}$

Another obstacle for SRA/WHO/local registration to be an effective signal of drug quality is their obscurity to consumers. Patients are unlikely to know which product is registered by whom, and any advertising of the registration status on drug package can be easily copied or

\footnotetext{
${ }^{32}$ Even for potentially fatal diseases like malaria, untreated (or treated with a fake) episode of disease has at most a fatality rate of 2-5\%, so most of the cases will be recovered from even a fake, and the patient none the wiser.

${ }^{33}$ The signaling effect of other drug regulations is even less clear: while greater penalty typically deters the intention to commit bad behavior, empirically greater penalty could arise in a country because that country suffers from a greater problem of counterfeit or substandard drugs. Similarly, price regulations may reduce the potential benefits of counterfeiting but weakens the ability for price to be an effective signal of drug quality, thus the correlation between price regulation and drug quality is unclear either.
} 
forged. The obscurity of SRA/WHO/local registration does not necessarily imply equal price, as a stringent registration itself could generate extra cost for the registered manufacturer. However, if a poor-quality product aims to mimic, it could easily mimic a registered product on price. This information problem highlights the importance of other non-price signals of quality .

One such non-price signal is the product's distribution channel. We argue that chain pharmacies are likely to have better quality control than independent stores for two reasons. First, the scale of chain operation offers a cost advantage in internal quality control. Largequantity and frequent encounters with the same supplier are likely to expose signs of problem if the supplier sells counterfeit or substandard products systematically; and one unit that identifies a problematic supplier can convey that information to other units of the same chain. In theory, large pharmacy chains can also test products before or after acquiring them, but the incentive to do so is likely weak especially if neither consumers nor regulators can discover quality problems and link them to chain identity (Cockburn et al. 2005).

Secondly, chain pharmacies may be better motivated to exercise internal quality control thanks to reputation concerns. Chains have invested more sunk costs in the business than momand-pop stores and a quality problem linked to one unit of the chain often spreads quickly to other units under the same logo. Both factors motivate chains to cherish their reputation in the eyes of consumers and regulators (Klein and Leffler 1981). However, the reputation mechanism is only effective if there is enough information to create and update reputation, which again depends on consumer ability to identify drug efficacy ex post and regulator ability to engage in market surveillance (see Bar-Isaac and Tadelis 2008 for a literature review on seller reputation).

In the absence of effective information from consumer experience, regulations and distribution channels are likely complements rather than substitutes in ensuring drug safety. A formal drug registration system may guide retailers towards registered products, and market surveillance may incentivize retailers to cherish their reputation and exercise tighter quality control when they acquire products from upstream suppliers. We are not aware of any academic evidence on the role of chain affiliation in drug safety, but the literature has documented quality or incentive difference between chains and independent stores in banking, restaurants, hotels, gas stations, and nursing homes (Brickley et al. 2003, Mazzero 2004, Png and Reitman 1995, Jin and Leslie 2009, Luca 2011, Brickeley, Lu and Wedig 2012). 
How product registration and chain affiliation interact in a producer's choice between counterfeit and substandard is another question. Assuming product registration is effective so that registered products are more likely to be of good quality, it will raise the price of registered products and therefore increase the potential profit of mimicking registered products. In the meantime, chain pharmacies may pay closer attention to the proof of product registration and the veracity of those supplying such products, making it difficult for counterfeit products to sneak into chain pharmacies. Because product registration usually focuses more on overall manufacturer legitimacy rather than repeated assessments of the quality of a specific product, it opens doors for legitimate manufacturers to substitute substandard products for good quality ones, especially if product registration is not accompanied by effective market surveillance. This also implies that chain pharmacies paying attention to product registration remain vulnerable to substandard production from legitimate manufacturers or near-perfect counterfeits of registered products.

Above all, we anticipate the following correlation between regulation, chain affiliation, drug price, and drug safety:

- Both product registration and the retailer's chain affiliation predict higher passing rate of the Minilab test and higher price. The chain effect is expected to be greater when the product is registered with local authority and when consumers are more able to read and report drug information.

- Passing rate and price are likely to decrease in the order of SRA approval, WHO prequalification, local product registration, and none of the above.

- Counterfeits can only exist in a pooling equilibrium, in which the counterfeit price is set the same as the authentic product it attempts to mimic. In comparison, substandard and good-quality products could coexist in a separate equilibrium, where substandard products are sold with a significant discount. If such a separate equilibrium exists, it is likely to appear in a market with significant demand for cheap drugs.

- Conditional on the products that fail the Minilab tests, it is unclear whether product registration and chain affiliation are correlated with more or less propensity of being counterfeits.

IV Data Analysis 
Out of the 1437 samples in our data, 1295 (90.1\%) passed the Minilab test, $59(4.1 \%)$ are counterfeits and the remaining $83(5.8 \%)$ are substandard. Visual inspection prior to the Minilab tests yielded 11 failures, and they all turned out to have no active ingredient and hence are classified as counterfeits.

Table 1 summarizes the other variables according to the visual and Minilab test results. Obviously, drugs that passed the Minilab test are more likely to come from a pharmacy that is affiliated with a pharmacy chain or looks trustworthy according to our shopper's subjective assessment. The countries/cities from which we purchased the non-failing drugs tend to be richer, of higher literacy, with harsher maximum penalty on drug counterfeiting, and more likely to have price regulations on prescription drugs. The non-failing samples are also more likely to be registered with local authorities, be prequalified by the WHO, or be approved by SRA (and be an innovator brand). More than 45 percent of the non-failing drugs came from Asia, another 39 percent from Africa, and a smaller percentage from Europe and the US. For drugs that failed, the vast majority (62.7\%) came from Africa followed by Asia. There were very few failures from the US and Europe.

The price difference between passing and failing drugs is substantial. On average, drugs that passed were priced at $\$ 8.90$ while drugs that failed had an average price of $\$ 4.41$. Within failures, counterfeits are $\$ 0.36$ more expensive than substandard drugs. For each counterfeit, we further record the price of the genuine product that it attempts to mimic and find that counterfeits are only priced $2.31 \%$ lower than the genuine price. This confirms the prediction that counterfeits must exist in a deceptive pooling equilibrium which entails similar price as the target of the counterfeit. The comparable prices of substandard products are hard to define because they do not necessarily pretend to be something else. To address this issue, we construct the average price of all passing generic Cipro of the same city-year in our sample and use it as the comparable price for the substandard. Unlike counterfeits, Table 1 shows that these substandard drugs are priced $30.4 \%$ lower than the comparable passing drugs. This large price gap may be large enough for some consumers to become suspicious about the quality of an extremely cheap Cipro, and for very price-sensitive consumers to sustain demand.

Half of our sampled drugs were imports from a manufacturing country that is different from the purchase country. While our purchase countries focus on low- and mid-income countries, $24.8 \%$ were made in US or Europe, and most of these products passed the Minilab 
test. India is clearly the biggest manufacturing country, accounting for $47.5 \%$ of our data. China manufactured $6.4 \%$ of our sample and another $18 \%$ came from Africa. A relatively small percentage of drugs (3.4\%) were obtained from other countries in Asia and South America. Comparing this distribution to the distribution of manufacturing countries for failing drugs only, it is clear that products from China and Africa are disproportionally more likely to be poor quality while products from India, US and Europe are disproportionally less likely to fail. Nevertheless, the absolute count of poor quality drugs is still large from India (51 of 142), simply due to India's large market share. Within failing drugs, Chinese and Indian products are more likely to be counterfeits while African products are more likely to be substandard. This is consistent with the argument that substandard drugs may co-exist with good-quality drugs but offer significant lower price to address local demand for cheap drugs.

Table 2 provides a more detailed tabulation of purchase and manufacturing countries. While we have data on specific countries of manufacture, we grouped countries within a broad region for ease of exposition. Hence Africa includes Angola, South Africa, Democratic Republic of Congo (DRC), Egypt, Ethiopia, Ghana, Kenya, Nigeria, Rwanda, Tanzania, Uganda, Zambia; South America includes Argentina, Brazil; Europe includes Belgium, Germany, Spain, Switzerland, Turkey, Russia, UK; and Other Asia includes Thailand, and Pakistan. As the final column in the table shows, the majority of countries rely on imports of Cipro rather than producing the drug domestically. Angola and Mozambique have close to $100 \%$ of the drug being imported from India, Europe or Africa. For most other countries, the percentage of imports varies from $55 \%$ (Kenya) to $84 \%$ (DRC). India is an exception in that it relies almost exclusively on domestic production, with imports accounting for less than $6 \%$ of the total sample. India is also one of the main manufacturers and exporters of Cipro to all the other countries. Out of 683 Indian made samples purchased, 450 were bought domestically and the rest were exports to other countries. Surprisingly, China also had a high fraction of imports (almost 65\%), the bulk of which came from India.

With the help of regulatory authorities and legitimate manufacturers whose products were faked, we discover 23 counterfeit products whose alleged manufacturing place differs from the actual manufacturing place, such as the above example of Ciprotab. In that example, the fake we 
bought from Lagos Nigeria is known by local authorities and VS International India (the producer of genuine Ciprotab) to be made in China. ${ }^{34}$

Table 3 tabulates price and quality outcomes by product registration and chain affiliation. Of the total sample of 1437, 92 are SRA approved (and carry innovator brand), 56 are WHO prequalified generics, 1084 are registered with the local government of the purchase country but not approved by SRA or WHO, and the remaining 205 are not registered anywhere. SRA approval and WHO prequalification are not necessarily mutually exclusive, but in our sample they were; and both are more selective than local registration. In fact, only one SRA approved drug in our sample is not locally registered and all the WHO prequalified drugs are locally registered. Consistent with the relatively stringent standards of SRA and WHO, we only find two failures with SRA/WHO approval and both of them are counterfeits. Due to the limit of the Minilab test, we do not have enough power to examine whether SRA-approved drugs are of higher quality than WHO-prequalified drugs. That being said, we do encounter three borderline passes for WHO-prequalified samples, which we suspect would not pass more stringent quality control methods.

For drugs without SRA or WHO approval, Table 3 shows that the passing drugs tend to concentrate in registered products from chain pharmacies. Of the total 811 chain purchases, only 17 (or 2.1\%) fail the Minilab test and most of these failures (11 or 64.7\%) are substandard. In contrast, of the total 626 non-chain purchases, 126 (or 20.1\%) fail the Minilab test and 57.1\% of these failures are substandard. Another interesting fact is that failing and locally registered products are more likely to be counterfeits, while failing and non-registered products are more likely to be substandard. This is probably because the higher price of registered products attracts counterfeiting. However, the extremely high price of SRA approved drugs - which is almost five times the price of other drugs - does not attract much counterfeiting in our sample. We believe this is partly because SRA approved manufacturers are active in fighting against counterfeits, with counterfeiters running a far greater risk of exposure if they fake SRA approved products, and additionally because the extremely high price may limit demand to more affluent

\footnotetext{
${ }^{34}$ VS International communicated with one of us (Bate), indicating they were happy for us to mention the fake of their product, which is why we discuss it here.
} 
consumers who are more likely to complain with poor product performance, which therefore may discourage the incentive to counterfeit. ${ }^{35}$

Table 4 presents probit regressions of quality on not only regulations and chain affiliation but also pharmacy assessment, local demographics, areas of purchasing countries (Asia and Africa), areas of manufacturing countries (India, China, Europe/USA), and a dummy of purchased before 2012. The reported coefficients are the marginal effects.

Columns 1 and 2 use the full sample. According to Column 1, both local product registration and chain affiliation increase the probability of passing the Minilab test, but the impact of SRA approval and WHO prequalification is close to zero. One interpretation is that the relatively more stringent standard of SRA/WHO approval does not increase basic drug quality beyond the main effects of local registration and chain pharmacy. Another possibility is that SRA/WHO approved drugs are of higher quality - for example with fewer contaminants or impurities conditional on the same amount of active ingredient - but our conservative Minilab test does not pick up the difference. Shopper assessment of the pharmacy is also positively associated with likelihood of success, suggesting that some non-chain pharmacies are able to signal their better quality by other consumer-observable attributes (e.g. size and cleanliness of the store). Drugs manufactured in India, Europe or USA are more likely to pass, while those from China are less likely to do so.

Column 2 adds two more variables. One interacts the dummy of chain affiliation with adult literacy rate. The coefficient is insignificant suggesting that product quality within chains is not different across high literacy and low literacy countries. The second variable interacts chain dummy with local product registration. As we expect, the coefficient is positive and significant, confirming the prediction that the positive chain effect on drug quality is greater for registered products because registration guides chain pharmacies to better identify products and carrying non-registered products may impose a risk on chain reputation. More interestingly, after we include the interaction of chain affiliation and product registration, the coefficient of chain affiliation alone is close to zero. This suggests that non-registered products sold in chain pharmacies are no better than non-registered products sold in independent stores.

\footnotetext{
${ }^{35}$ As shown in Qian (2008), Qian (2012) and Grossman and Shapiro (1988b), brand-name manufacturers may use high price and new product introductions to preempt counterfeits at the high end of product quality.
} 
Columns 3-4 of Table 4 use only the failing sample to test for the likelihood of observing a counterfeit or a substandard product. Note that the failing sample used in these regressions is 140 rather than 142. This is because there are only two failures under SRA approval and WHO prequalification, both of them are fake, one with SRA approval and one with WHO prequalification. This implies that SRA and WHO approvals perfectly predict fake and therefore both SRA and WHO variables are dropped from the failed sample regressions.

According to Column 3 of Table 4, local product registration is likely to predict counterfeit while chain affiliation is likely to predict substandard. How could this be? One explanation is that registered products are sold at higher price (confirmed in Table 5) and thus attract counterfeits. In comparison, chain pharmacies are more able to use procurement wholesalers to avoid fakes, but chains find it difficult to tell whether products sold by wholesalers from a legitimate manufacturer are substandard or not. Country also has some power predicting counterfeit versus substandard: products purchased in Africa were significantly more likely to be substandard and those made in China were significantly more likely to be counterfeit.

Column 4 adds the interaction of chain dummy with adult literacy rate and local registration. Their coefficients suggest that, within chain failures, locally registered products are more likely to be counterfeits and failures in higher educated countries are more likely to be substandard. Readers should be cautious about these results because they are identified from very few (17) failures from chain pharmacies.

Table 5 presents regressions of log price on product quality and other variables. Columns 1-2 show that passing drugs are priced significantly higher than counterfeit and substandard products, but most of this difference comes from the signaling effect of product registration and chain affiliation. Once we control for SRA/WHO/local registration and chain dummy, consumers cannot tell the quality difference between passing, counterfeit and substandard drugs. Within these effective signals, SRA approval (innovator brand) implies huge price premium (64\%), local registration and chain affiliation imply 18.3\%-26\% higher price, but WHO prequalification implies no significant premium beyond what local registration and chain affiliation have done. ${ }^{36}$ The interaction of chain dummy with literacy rate and local registration has little effect on price (Column 3).

\footnotetext{
${ }^{36}$ Recall that all WHO prequalified products are locally registered and most of them are sold in chain pharmacies.
} 
The last two columns of Table 5 include purchase country fixed effects, which absorb local demographics. These two regressions suggest that passing and counterfeit drugs are priced significantly higher than substandard, although consumers cannot observe the actual quality. How could this be consistent with the close-to-zero coefficients of passing and counterfeit indicators when the price regression does not include country fixed effects? This is because the distribution of counterfeit and substandard drugs is not even across countries (even after conditioning on local GDP per capita and literacy rate): failing drugs purchased from Africa are disproportionally substandard and failures from Asia and Latin American are more likely to be counterfeits.

The selection of counterfeit and substandard drugs by purchase country is further confirmed in Table 6, where we compare the price of counterfeits with corresponding genuine products and compare the price of the substandard with comparable passing generics. Both comparisons are within the city-year of purchase, thus controlling for the country-specific selection of counterfeit and substandard drugs. All four columns of Table 6 - with or without chain dummy interactions, with or without purchase country fixed effects - indicate that counterfeits are priced over $26 \%$ higher than the substandard. This is consistent with the data summary of Table 1, which shows that counterfeits are priced similar to the corresponding genuine products but substandard ones are priced 30\% lower than comparable generics. In economic terms, this suggests that counterfeits mimic passing drugs in a pooling equilibrium but substandard and passing drugs co-exist in a separate equilibrium with the substandard targeting the lower-end of the market demand.

\section{Discussion}

Using 1437 drug samples from 18 countries, we make the first academic attempt to distinguish counterfeit, substandard and good-quality drugs by active ingredient, and assess both price and non-price signals of such quality distinction. There are four main findings: First of all, $9.88 \%$ of our samples are found to have less than $80 \%$ of the correct active ingredient. Within failures, $41.5 \%$ are counterfeits with zero active ingredient and the other $58.5 \%$ are substandard with non-zero but less than $80 \%$ of correct active ingredient. Secondly, non-price signals such as product registration and chain pharmacy predict higher passing rate and higher price, suggesting that the registration process effectively identifies legitimate manufacturers and chain pharmacies 
are more capable of screening out poor quality drugs than independent stores. Third, conditional on failures, product registration is likely to predict counterfeit while chain affiliation is likely to predict substandard. Moreover, counterfeit drugs are priced similar to their genuine counterparts, but substandard drugs are $30 \%$ cheaper than comparable passing generics in the local market. These findings demonstrate remarkable quality differentiation by observable price and non-price signals, while also allow a pooling outcome where counterfeits mimic passing drugs in observable attributes. They suggest that substandard and counterfeit manufacturers are likely to follow different business strategies and find their ways in different distribution channels.

Our findings have significant implications for final consumers. Since detecting poor quality products without laboratory analysis is very difficult even for an expert ${ }^{37}$, consumers are heavily reliant on proxies for quality. Among all the effective signals found in our paper, chain affiliation is probably the most visible to consumers. Pharmacists pay significant attention to procurement systems, and many middle class consumers in emerging markets appear to be aware of this, becoming reliant on one particular pharmacy or pharmacy chain as a trusted source of medicines (Bate 2012). In this way they may avoid a lot of the counterfeit products. Once the choice of pharmacy is made, avoiding substandard products is easier by demanding more expensive generic products or innovator brands. In short, buying more expensive products from chain pharmacies significantly lowers the risk of getting inferior drugs.

Our findings also present significant lessons for policy makers. The strong association between product registration and drug quality in our sample demonstrates that the process of registration is of significant value, even allowing for the fact that counterfeiters are more likely to target registered products. Local product registration also assists pharmacies to identify good products and may help direct the better performance of chain pharmacies discussed above. There is obviously room for improvement in local registration, since far more locally registered products fail than those prequalified by WHO or SRA, and this may indicate that manufacturers are flouting quality standards because the local regulator is not undertaking enough surveillance of the products on the market to remove products breaking the rules.

The registration and regulatory processes can only combat counterfeit products with the assistance of good anti-counterfeit laws and their enforcement by separate police authorities.

\footnotetext{
${ }^{37}$ In our data, less than one percent of all products or less than ten percent of poor quality products were identified to be counterfeits by visual inspection.
} 
Increasing post market surveillance would help regulators identify more counterfeit problems, but without assistance from law enforcement authorities such expenditures might not show results. The information learned in this study may assist regulators to combat substandard products. Substandard drugs may be made by legal producers, thus control of them is the role of the drug regulator. Increasing product surveillance should identify substandard products, and regulators can warn, fine and ultimately ban producers of bad products if they continue to flout quality standards.

Currently, many regulators do not pay keen attention to product price on the private market, and the attention to price can be even lacking in government tenders to supply hospitals and clinics directly. Our research indicates that price monitoring can be useful: the too-good-tobe-true drug prices may well indicate poor quality products. Given this observation, surveillance for substandard products can be more effective if it targets the low price end of the market. This is especially important because the evidence in this study shows that chain pharmacies are less able to combat lower price substandard products than fakes.

Of course banning low priced low-quality products has to be addressed carefully, since these products may be the only ones the poorest can afford and raising the minimum quality standard might be welfare reducing, especially for those who are more sensitive to price and prefer low quality products due to affordability (Leland 1979).

But maintaining minimum standards is important, especially because very poor quality drugs do not help the patient, may increase resistance at the population level, and vastly increase healthcare costs. Some infections like HIV and tuberculosis are relatively cheap to treat initially, but resistant strains increase costs from hundreds of dollars to tens of thousands per patient (Fitzpatrick and Floyd 2012).

How does one address this dilemma? Brazil has a partial solution. It has a lower standard set of products on the market, called similares, which are clearly identified as not being proven generics, and which are noticeably cheaper than generics. ${ }^{38}$ Brazil passed a law in 2002 outlawing these products by 2013. This allowed local manufacturers time to improve facilities to make proven generics, whilst at the same time helping consumers appreciate that similares were riskier cheaper products (Bate 2012). This approach allows market segmentation by price and

\footnotetext{
${ }^{38}$ Since similares are often sold in specific shops selling only similares they were not targeted in this study since no city (other than Sao Paolo, Brazil) studied has such an obviously segmented market.
} 
quality, until increased wealth drives the poorer products from the market. In most other countries consumers have to guess, often based on price or distribution channel, which products are less proven.

The "similares" solution does not work for drugs of acute infectious diseases with known resistance problems. Consequently, to combat poor quality drugs to treat these diseases relies more on stringent registration and intensive market surveillance. Since such a policy will increase the cost of medication, it might be worthwhile to target these diseases for free or lower price interventions in public clinics. These diseases are indeed combated with free clinics in many countries, including Brazil, but not for the stated reason of limiting market segmentation by drug quality and price where resistance is likely to be critical. A more overt understanding of the dynamics of this dilemma might encourage greater market segmentation by quality and price for drugs for diseases with low resistance problems.

Given the near universally good quality of SRA and WHO approved products, governments in emerging markets may find it more cost effective to automatically register these products with no testing of products prior to approval. This will free up resources and allow more focused attention on prior testing of products that are less likely to be of high quality. However, this does not necessarily imply zero need for ex post surveillance of SRA or WHO approved products. SRA/WHO approved products can be target of counterfeits, especially if SRA or WHO does not have enough resources to conduct surveillance in the local market of a purchase country.

All the above discussions are subject to at least two caveats. First, this study is based on one popular antibiotic in 22 cities and 18 countries. Although we have no reason to expect the results to differ drastically for other drug types - in fact our previous work (Bate, Jin and Mathur 2011) has shown for eight drug types that high-quality drugs are more likely to be registered and of higher price - further study is needed to confirm these findings for a broader set of drugs and countries.

Second, any policy adjustment is subject to Lucas' critique. When regulators adjust their enforcement target and strength, it may trigger a strategy change in counterfeit and substandard drug producers. For example, companies that include security devices (holograms and special inks that are hard to copy etc.) or track and trace devices (bar codes, scratch pads with consumer authentication by phone) and otherwise make an effort to protect their brand are more likely to 
be left alone by counterfeiters. While counterfeiters are more attracted to branded drugs because of the high value returns, the expected costs of discovery, arrest and prosecution are probably higher, so only a very few counterfeiters will likely get into this area. This reminds us of a classical inspection game. According to Dresher (1962), Maschler (1966) and their follow-ups, the only equilibrium in a classical inspection game is inspectors randomizing enforcement and potential criminals randomizing between cheating and no-cheating. ${ }^{39}$ This implies that, while studies like ours may help government regulators to better target enforcement, it is also important to change enforcement in an unpredictable way in order to eliminate any safe harbor for counterfeit and substandard drug producers.

\footnotetext{
${ }^{39}$ In the original example of the inspection game, it is between an inspector that chooses whether to perform an inspection and a smuggler that chooses whether to attempt an illegal act.
} 


\section{References}

Bar-Isaac, Heski and Steve Tadelis (2008) "Seller Reputation" Foundations and Trends in Microeconomics, 4(4).

Bate, Roger, Hess, K, Mooney, L. "Medicine Registration and Medicine Quality: A Preliminary Analysis of Key Cities in Emerging Markets", Research and Reports in Tropical Medicine, December 2010, vol 1. Pp 89-93, doi 10.2147/RRTM. S15199.

Bate, Roger, Emily Putze, Sarah Naoshy, Alexandra McPherson, and Lorraine Mooney. "Drug Registration - a necessary but not sufficient condition for good quality drugs - a preliminary analysis of 12 countries." Africa Fighting Malaria Working Paper (Africa Fighting Malaria), 2010.

Bate, Roger, Richard Tren, and Jasson Urbach. Still Taxed to Death: An Analysis of Taxes and Tariffs on Medicines, Vaccines and Medical Devices. Washington, DC: AEI-Brookings Joint Center for Regulatory Studies, 2006.

Bate R, Coticelli P, Tren R, Attaran A. "Antimalarial drug quality in the most severely malarious parts of Africa - A six country study." PLoS ONE. 2008;3(5): e2132. doi:10.1371/journal.pone.0002132.

Bate R, Hess K. "Anti-malarial drug quality in Lagos and Accra - a comparison of various quality assessments.” Malar J. 2010;9:157. doi:10.1186/1475-2875-9-157.

Bate R, Tren R, Mooney L, et al. Pilot Study of Essential Drug Quality in Two Major Cities in India. PLoS ONE. 2009;4(6): e6003.;doi:10.1371/journal.pone.0006003.

Bate R, Tren R, Hess, K, Mooney, L, Porter, K, Pilot study comparing technologies to test for substandard drugs in field settings, African Journal of Pharmacy and Pharmacology Vol.3(4), pp.165-170 April, 2009.

Bate, Roger; Ginger Zhe Jin and Aparna Mathur (2011) "Does Price Reveal Poor-Quality Drugs? Evidence from 17 Countries" the Journal of Health Economics, 30(6): 1150-1163.

Bate, Roger (2012) Phake: the Deadly World of Falsified and Substandard Medicines, Publisher: American Enterprise Institute Press.

Bate, Roger. et al "Substandard and Falsified Anti-Tuberculosis Drugs - A Preliminary Field Analysis." The International Journal of Tuberculosis and Lung Disease. forthcoming.

Brickley, James A.; J.S. Linck and C.W. Smith (2003) "Boundaries of the Firm: Evidence from the Banking Industry" Journal of Financial Economics, 18(2): 401-20.

Brickley, James A.; Susan Feng Lu; and Gerard J. Wedig (2012) "Ownership, Branding and Multiple Audience Concerns: Evidence from Nursing Homes.” Rochester University working paper.

Caudron, J.M.; N. Ford; M. Henkens; C. Mace; R. Kiddle-Monroe and J. Pinel (2008) "Substandard medicines in resource-poor settings: a problem that can no longer be ignored" Tropical Medicine and International Health, 13(8): 1062-1072.

Cockburn, R, PN Newton, EK Agyarko, D Akunyili, and NJ White. "The Global Threat of Counterfeit Drugs: Why Industry and Governments Must Communicate the Dangers." PLoS Medicine 2(4): e100, 2005.

Dresher, M. (1962) "A Sampling Inspection Problem in Arms Control Agreements: A GameTheoretic Analysis” Memorandum RM-2972-ARPA, The RAND Corporation, Santa Monica, California.

Fitzpatrick Christopher and Katherine Floyd (2012) "A systematic review of the cost and cost effectiveness of treatment for multidrug resistant tuberculosis", Pharmacoeconomics, (1):6380 . 
Grossman, Gene and Carl Shapiro (1988a) "Foreign Counterfeiting of Status Goods" The Quarterly Journal of Economics, 103(1): 79-100.

Grossman, Gene and Carl Shapiro (1988b) "Counterfeit-Product Trade" American Economic Review, 78(1): 59-75.

Jin, Ginger Zhe and Phillip Leslie (2009) "Reputational Incentives for Restaurant Hygiene" American Economic Journal - Microeconomics, 1(1): 237-67.

Kelesidis, Theodore; Iosif Kelesidis; Petros I. Rafailidis and Matthew E. Falagas (2007) "Counterfeit or Substandard Antimicrobial Drugs: A Review of the Scientific Evidence" Journal of Antimicrobial Chemotherapy 60: 214-236.

Klein, Benjamin and K.B. Leffler (1981) "The Role of Market Forces in Assuring Contractual Perforamnce" Journal of Political Economy, 89(4): 615-41.

Leland, Hayne E. (1979) "Quacks, Lemons, and Licensing: A Theory of Minimum Quality Standards” Journal of Political Economy, 87(6): 1328-1346.

Luca, Michael (2012) "Reviews, Reputation, and Revenue: The Case of Yelp.com" Harvard Business School working paper.

Maschler, M. (1966) "A Price Leadership Method for Solving the Inspector's Non-constant Sum Game" Naval Research Logistics Quarterly 13: 11-33.

Mazzeo, Michael J. (2004) "Retail Contracting and Organizational Form: Alternatives to Chain Affiliation in the Motel Industry" Journal of Economics \& Management Strategy, 13(4): 599615.

Milgrom, Paul and J. Roberts (1986) "Price and Advertising Signals of Product Quality" Journal of Political Economy 94: 796-821.

Nayyar, Gaurvika M L; Breman, Joel G; Newton, Paul N; Herrington, James. "Poor-quality antimalarial drugs in southeast Asia and sub-Saharan Africa." The Lancet. Vol. 12, June 2012.

Newton, Paul N; Cockburn, Robert; Agyarko, E Kyeremateng; Akunyili, Dora; White, Nicholas J. "The Global Threat of Counterfeit Drugs: Why Industry and Governments Must Communicate the Dangers." PLoS Medicine. March 14, 2005. http://www.plosmedicine.org/article/info\%3Adoi\%2F10.1371\%2Fjournal.pmed.0020100

Newton, Paul N. Green, Michael D; Fernandez, Facundo M. "Impact of poor-quality medicines in the 'developing' world." Trends in Pharmacological Sciences. Vol. 31. Issue 3, March 2010, Pgs. 99-101. http://www.sciencedirect.com/science/article/pii/S016561470900203X

Newton, Paul N. Green, Michael D; Fernandez, Facundo M. "Impact of poor-quality medicines in the 'developing' world." Trends in Pharmacological Sciences. Vol. 31. Issue 3, March 2010, Pgs. 99-101. http://www.sciencedirect.com/science/article/pii/S016561470900203X.

Newton PN, Amin AA, Bird C, Passmore P, Dukes G, et al. (2011) "The Primacy of Public Health Considerations in Defining Poor Quality Medicines.” PLoS Med 8(12): e1001139. doi:10.1371/journal.pmed.1001139.

Oxfam, "Eye on the Ball Medicine regulation - not IP enforcement - can best deliver quality medicines" 143 Oxfam Brief Paper, February 2, 2011.

Pincock, S. (2003) "WHO tries to tackle problem of counterfeit medicines in Asia" British Medical Journal 327: 1126.

Png, I. P. L. and Reitman, D. (1995, "Why Are Some Products Branded and Others Not." Journal of Law \& Economics, 38(1), pp. 207-24.

Qian, Yi (2008) "Impacts of Entry by Counterfeiters" The Quarterly Journal of Economics 123(4): 1577-1609. 
Qian, Yi (2012) "Brand Management and Strategies Against Counterfeits", Northwestern University working paper.

USAID (2009) "Growing Threat of Substandard and Counterfeit Medicines in Developing Countries Addressed by New USAID-USP Cooperative Agreement" USAID press release, accessed at http://www.usaid.gov/press/releases/2009/pr091026_1.html, on April 22, 2012.

Wolinsky, Asher. "Prices as Signals of Product Quality."The Review of Economic Studies Vol 50 No.4, 1983: 647-658.

World Health Organization (2010), "Medicines: spurious/falsely-labelled/ falsified/counterfeit (SFFC) medicines", fact sheet 275, accessed at http://www.who.int/mediacentre/factsheets/fs275/en/index.html, on April 22, 2012.

World Health Organization (2011), "Report of the Working Group of Member States on Substandard/Spurious/Falsely-Labelled/Falsified/Counterfeit Medical Products", March 11, 2011, accessed at http://apps.who.int/gb/ssffc/pdf_files/A_SSFFC_WG5-en.pdf on Oct. 11, 2012. 


\section{Figure 1: Images of genuine and fake Ciprotab}

A: Front of a fake package (not distinguishable from a genuine package)

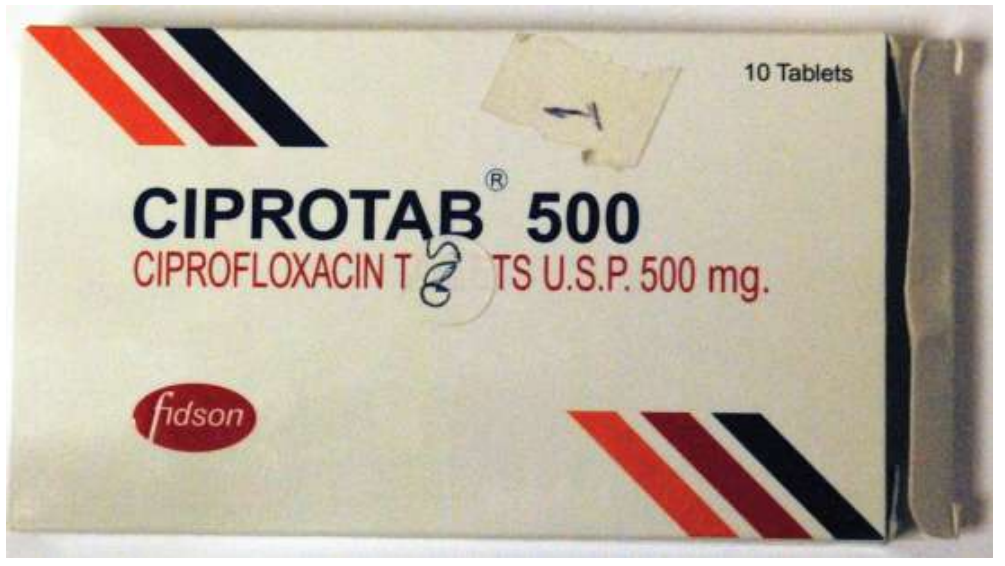

B: Back of a genuine package

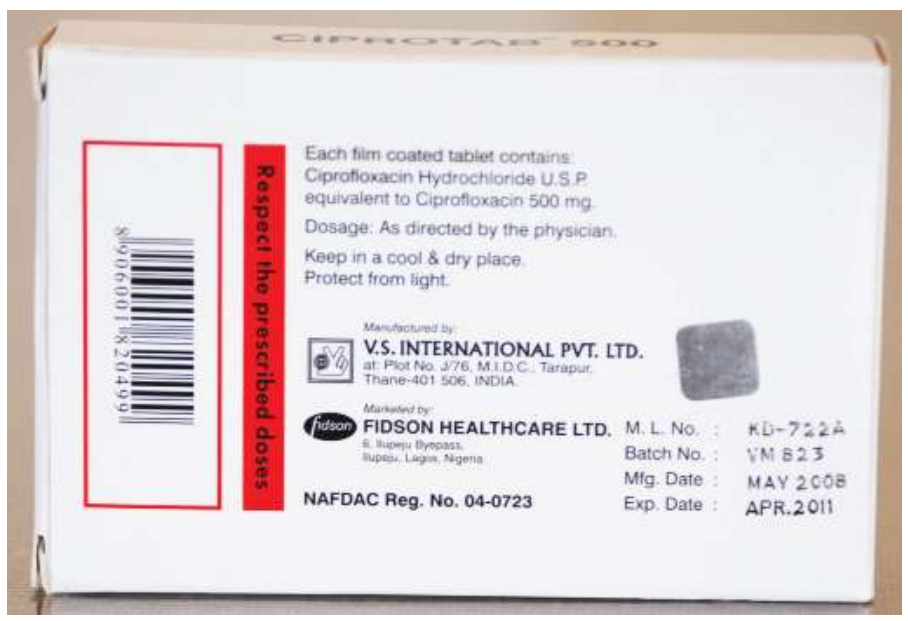

C: Back of a fake package

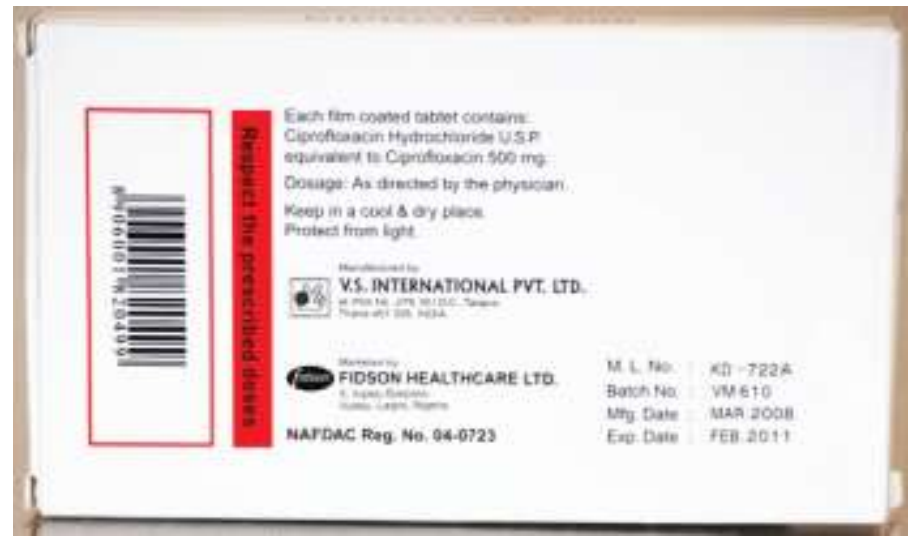


Table 2 Country of purchase versus country of manufacturing

\begin{tabular}{|c|c|c|c|c|c|c|c|c|c|}
\hline \multirow[b]{2}{*}{$\begin{array}{l}\text { Country of } \\
\text { purchase }\end{array}$} & \multicolumn{7}{|c|}{ Country of Manufacturing } & \multirow[b]{2}{*}{ Total } & \multirow[b]{2}{*}{$\begin{array}{c}\% \\
\text { import }\end{array}$} \\
\hline & Africa & USA & $\begin{array}{l}\text { South } \\
\text { America }\end{array}$ & China & India & $\begin{array}{l}\text { Other } \\
\text { Asia }\end{array}$ & Europe & & \\
\hline Angola & 10 & 2 & 0 & 3 & 11 & 0 & 30 & 56 & $98.21 \%$ \\
\hline Brazil & 0 & 4 & 25 & 0 & 18 & 0 & 23 & 70 & $67.14 \%$ \\
\hline China & 0 & 8 & 0 & 27 & 24 & 0 & 17 & 76 & $64.47 \%$ \\
\hline DRC & 11 & 0 & 0 & 4 & 8 & 0 & 2 & 25 & $84.00 \%$ \\
\hline Egypt & 32 & 0 & 0 & 3 & 15 & 0 & 13 & 63 & $63.49 \%$ \\
\hline Ethiopia & 23 & 0 & 0 & 4 & 11 & 0 & 4 & 42 & $64.29 \%$ \\
\hline Ghana & 28 & 0 & 0 & 2 & 16 & 0 & 10 & 56 & $67.86 \%$ \\
\hline India & 0 & 6 & 0 & 16 & 450 & 0 & 6 & 478 & $5.86 \%$ \\
\hline Kenya & 27 & 0 & 0 & 5 & 13 & 0 & 11 & 56 & $55.36 \%$ \\
\hline Mozambique & 12 & 0 & 0 & 0 & 6 & 0 & 12 & 30 & $100.00 \%$ \\
\hline Nigeria & 25 & 0 & 0 & 4 & 17 & 2 & 15 & 63 & $66.67 \%$ \\
\hline Russia & 0 & 2 & 0 & 4 & 9 & 0 & 55 & 70 & $72.86 \%$ \\
\hline Rwanda & 15 & 0 & 0 & 2 & 10 & 0 & 5 & 32 & $81.25 \%$ \\
\hline Tanzania & 27 & 0 & 0 & 5 & 16 & 0 & 15 & 63 & $76.19 \%$ \\
\hline Thailand & 0 & 13 & 0 & 11 & 25 & 19 & 8 & 76 & $75.00 \%$ \\
\hline Turkey & 0 & 0 & 0 & 0 & 8 & 0 & 62 & 70 & $65.71 \%$ \\
\hline Uganda & 24 & 0 & 0 & 2 & 11 & 0 & 19 & 56 & $75.00 \%$ \\
\hline Zambia & 25 & 0 & 0 & 0 & 15 & 0 & 15 & 55 & $76.36 \%$ \\
\hline Total & 259 & 35 & 25 & 92 & 683 & 21 & 322 & 1437 & $50.10 \%$ \\
\hline$\%$ of Export & $40.15 \%$ & $100 \%$ & $8.00 \%$ & $70.65 \%$ & $34.11 \%$ & $9.52 \%$ & $86.65 \%$ & & \\
\hline
\end{tabular}


Table 3: Product registration and chain affiliation

\begin{tabular}{|c|c|c|c|c|c|c|}
\hline & \multicolumn{3}{|c|}{ Non-Chain } & \multicolumn{3}{|c|}{ chain } \\
\hline & $\mathrm{n}$ & $\%$ & price & $\mathrm{n}$ & $\%$ & Price \\
\hline \multicolumn{7}{|l|}{ SRA approved } \\
\hline Total & 3 & & 8.54 & 89 & & 33.04 \\
\hline Pass & 3 & $100 \%$ & 8.54 & 88 & $98.8 \%$ & 33.19 \\
\hline Substandard & 0 & - & - & 0 & - & - \\
\hline Counterfeit & 0 & - & - & 1 & $1.12 \%$ & 19.76 \\
\hline \multicolumn{7}{|l|}{$\begin{array}{l}\text { WHO prequalified } \\
\text { But not SRA approved }\end{array}$} \\
\hline Total & 10 & & 6.64 & 46 & & 6.60 \\
\hline Pass & 9 & $90 \%$ & 5.45 & 46 & $100 \%$ & 6.60 \\
\hline Substandard & 0 & - & - & - & & \\
\hline Counterfeit & 1 & $10 \%$ & 17.44 & 0 & - & - \\
\hline \multicolumn{7}{|l|}{$\begin{array}{l}\text { Local registered but not } \\
\text { SRA/WHO approved }\end{array}$} \\
\hline Total & 425 & & 3.87 & 659 & & 9.59 \\
\hline Pass & 357 & $84 \%$ & 3.81 & 649 & $98.5 \%$ & 9.64 \\
\hline Substandard & 30 & $7.06 \%$ & 3.78 & 6 & $0.91 \%$ & 7.59 \\
\hline Counterfeit & 38 & $8.94 \%$ & 4.54 & 4 & $0.62 \%$ & 4.37 \\
\hline \multicolumn{7}{|l|}{ Not registered anywhere } \\
\hline Total & 188 & & 3.70 & 17 & & 8.56 \\
\hline Pass & 131 & $69.7 \%$ & 3.85 & 12 & $70.6 \%$ & 8.18 \\
\hline Substandard & 42 & $22.3 \%$ & 3.50 & 5 & $29.4 \%$ & 9.47 \\
\hline Counterfeit & 15 & $7.98 \%$ & 3.04 & 0 & - & - \\
\hline
\end{tabular}




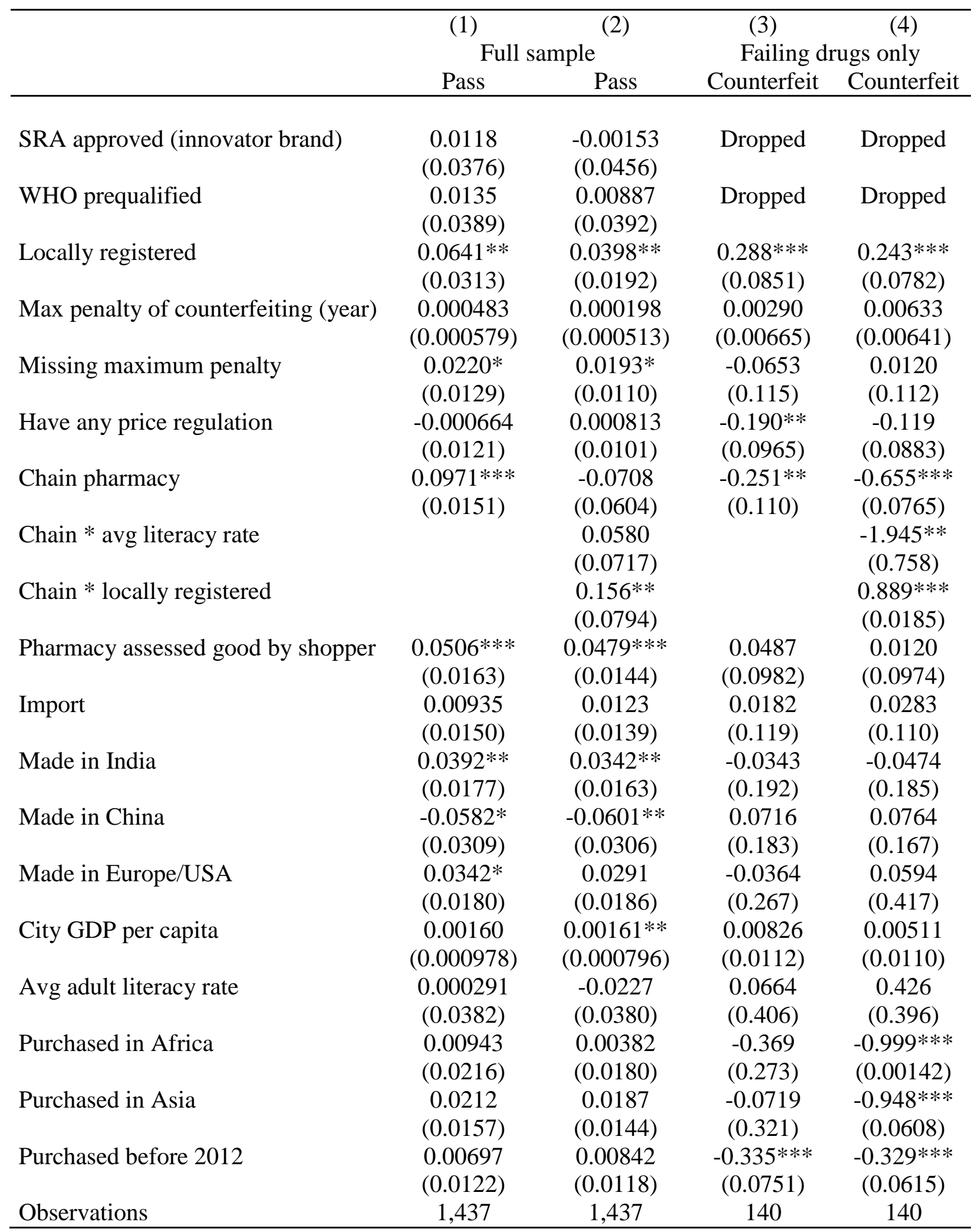

Robust standard errors in parentheses. Errors are clustered by purchase country. $* * * \mathrm{p}<0.01, * * \mathrm{p}<0.05, * \mathrm{p}<0.1$. 
Table 5 Price regressions

\begin{tabular}{|c|c|c|c|c|c|}
\hline & $\begin{array}{c}(1) \\
\text { Log price }\end{array}$ & $\begin{array}{c}(2) \\
\text { Log price }\end{array}$ & $\begin{array}{c}(3) \\
\text { Log price }\end{array}$ & $\begin{array}{c}(4) \\
\text { Log price }\end{array}$ & $\begin{array}{c}(5) \\
\text { Log price }\end{array}$ \\
\hline \multirow[t]{2}{*}{ Pass } & $0.165 * * *$ & 0.0585 & 0.0651 & $0.107 * *$ & $0.112 * *$ \\
\hline & $(0.0526)$ & $(0.0525)$ & $(0.0512)$ & $(0.0447)$ & $(0.0413)$ \\
\hline \multirow[t]{2}{*}{ Counterfeit } & 0.0344 & 0.0161 & 0.0289 & $0.128 * *$ & $0.142 * *$ \\
\hline & $(0.0599)$ & $(0.0665)$ & $(0.0682)$ & $(0.0567)$ & $(0.0536)$ \\
\hline \multirow{2}{*}{$\begin{array}{l}\text { SRA approved } \\
\text { (innovator brand) }\end{array}$} & & $0.640 * * *$ & $0.638 * * *$ & $0.628 * * *$ & $0.620 * * *$ \\
\hline & & $(0.145)$ & $(0.146)$ & $(0.130)$ & $(0.128)$ \\
\hline \multirow[t]{2}{*}{ WHO prequalified } & & 0.0322 & 0.0353 & 0.0612 & 0.0626 \\
\hline & & $(0.0548)$ & $(0.0535)$ & $(0.0466)$ & $(0.0441)$ \\
\hline \multirow[t]{2}{*}{ Locally registered } & & $0.183 * * *$ & $0.179 * * *$ & $0.0606 *$ & 0.0364 \\
\hline & & $(0.0607)$ & $(0.0595)$ & $(0.0291)$ & $(0.0262)$ \\
\hline \multirow{2}{*}{$\begin{array}{l}\text { Max penalty of } \\
\text { counterfeiting (year) }\end{array}$} & -0.00693 & -0.00395 & -0.00395 & $-0.0477 * * *$ & $-0.0500 * * *$ \\
\hline & $(0.0129)$ & $(0.0128)$ & $(0.0128)$ & $(0.00387)$ & $(0.00400)$ \\
\hline \multirow{2}{*}{$\begin{array}{l}\text { Missing maximum } \\
\text { penalty }\end{array}$} & $-0.540 *$ & -0.405 & -0.403 & $-1.041 * * *$ & $-1.057 * * *$ \\
\hline & $(0.307)$ & $(0.299)$ & $(0.299)$ & $(0.0790)$ & $(0.0794)$ \\
\hline \multirow[t]{2}{*}{ Have any price regulation } & 0.0622 & 0.0699 & 0.0746 & $-0.497 * * *$ & $-0.574 * * *$ \\
\hline & $(0.170)$ & $(0.167)$ & $(0.167)$ & $(0.0556)$ & $(0.0683)$ \\
\hline \multirow[t]{2}{*}{ Chain pharmacy } & & $0.260 * * *$ & -0.0591 & $0.232 * * *$ & $-0.362 *$ \\
\hline & & $(0.0496)$ & $(0.308)$ & $(0.0365)$ & $(0.187)$ \\
\hline \multirow[t]{2}{*}{ Chain $*$ avg literacy rate } & & & 0.456 & & $0.602 * *$ \\
\hline & & & $(0.340)$ & & $(0.229)$ \\
\hline \multirow[t]{2}{*}{ Chain * locally registered } & & & -0.0106 & & 0.167 \\
\hline & & & $(0.138)$ & & $(0.106)$ \\
\hline \multirow{2}{*}{$\begin{array}{l}\text { Pharmacy assessed good } \\
\text { by shopper }\end{array}$} & $0.303 * * *$ & $0.134 * *$ & $0.153 * *$ & $0.107 * *$ & $0.134 * *$ \\
\hline & $(0.0705)$ & $(0.0588)$ & $(0.0620)$ & $(0.0464)$ & $(0.0501)$ \\
\hline \multirow[t]{2}{*}{ Import } & $0.378 * *$ & $0.317 * *$ & $0.314 * *$ & -0.0438 & -0.0452 \\
\hline & $(0.136)$ & $(0.129)$ & $(0.130)$ & $(0.0644)$ & $(0.0634)$ \\
\hline \multirow[t]{2}{*}{ Made in India } & $-0.433 * *$ & $-0.355 * *$ & $-0.349 *$ & 0.00889 & 0.0174 \\
\hline & $(0.182)$ & $(0.168)$ & $(0.169)$ & $(0.0753)$ & $(0.0742)$ \\
\hline \multirow[t]{2}{*}{ Made in China } & $-0.446 * *$ & $-0.316^{* *}$ & $-0.297 * *$ & -0.123 & -0.0991 \\
\hline & $(0.167)$ & $(0.138)$ & $(0.133)$ & $(0.108)$ & $(0.107)$ \\
\hline \multirow[t]{2}{*}{ Made in Europe/USA } & 0.255 & 0.0288 & 0.0243 & $0.402 * * *$ & $0.392 * * *$ \\
\hline & $(0.183)$ & $(0.186)$ & $(0.187)$ & $(0.0938)$ & $(0.0963)$ \\
\hline \multirow[t]{2}{*}{ Purchased before 2012} & 0.0051 & 0.0318 & 0.0304 & 0.00867 & 0.0111 \\
\hline & $(0.0475)$ & $(0.0441)$ & $(0.0448)$ & $(0.0323)$ & $(0.0317)$ \\
\hline \multirow[t]{2}{*}{ City GDP per capita } & 0.0156 & 0.0210 & 0.0204 & & \\
\hline & $(0.0230)$ & $(0.0219)$ & $(0.0221)$ & & \\
\hline \multirow[t]{2}{*}{ Avg adult literacy rate } & $2.334 * * *$ & $2.392 * * *$ & $2.160 * *$ & & \\
\hline & $(0.783)$ & $(0.755)$ & $(0.745)$ & & \\
\hline \multirow[t]{2}{*}{ Purchased in Africa } & -0.0233 & 0.0756 & 0.0983 & & \\
\hline & $(0.651)$ & $(0.612)$ & $(0.609)$ & & \\
\hline \multirow[t]{2}{*}{ Purchased in Asia } & $-0.887 *$ & $-0.912 *$ & $-0.901 *$ & & \\
\hline & $(0.471)$ & $(0.439)$ & $(0.434)$ & & \\
\hline Country FE & No & No & No & Yes & Yes \\
\hline Observations & 1,437 & 1,437 & 1,437 & 1,437 & 1,437 \\
\hline R-squared & 0.810 & 0.842 & 0.843 & 0.923 & 0.924 \\
\hline
\end{tabular}

Robust standard errors in parentheses, errors clustered by purchase country. $* * * \mathrm{p}<0.01, * * \mathrm{p}<0.05,{ }^{*} \mathrm{p}<0.1$. 
Table 6 Price of failing drugs as compared to comparable passing drugs in the same city-year

\begin{tabular}{|c|c|c|c|c|}
\hline & (1) & $(2)$ & (3) & (4) \\
\hline & \multicolumn{4}{|c|}{ Ln(price/comparable price) } \\
\hline \multirow[t]{2}{*}{ Counterfeit } & $0.371 * * *$ & $0.367 * * *$ & $0.362 * * *$ & $0.363 * * *$ \\
\hline & $(0.0697)$ & $(0.0748)$ & $(0.0729)$ & $(0.0775)$ \\
\hline \multirow{2}{*}{$\begin{array}{l}\text { SRA approved } \\
\text { (innovator brand) }\end{array}$} & -0.220 & -0.361 & $-0.306^{*}$ & $-0.498 *$ \\
\hline & $(0.185)$ & $(0.229)$ & $(0.163)$ & $(0.240)$ \\
\hline \multirow[t]{2}{*}{ WHO prequalified } & 0.118 & 0.0200 & 0.180 & 0.0780 \\
\hline & $(0.148)$ & $(0.121)$ & $(0.136)$ & $(0.164)$ \\
\hline \multirow[t]{2}{*}{ Locally registered } & $0.0973 *$ & 0.0700 & 0.0939 & 0.0753 \\
\hline & $(0.0530)$ & $(0.0529)$ & $(0.0560)$ & $(0.0553)$ \\
\hline \multirow{2}{*}{$\begin{array}{l}\text { Max penalty of } \\
\text { counterfeiting (year) }\end{array}$} & -0.000870 & -0.00112 & -0.00365 & -0.00697 \\
\hline & $(0.00316)$ & $(0.00350)$ & $(0.00365)$ & $(0.00469)$ \\
\hline \multirow{2}{*}{$\begin{array}{l}\text { Missing maximum } \\
\text { penalty }\end{array}$} & 0.0776 & 0.0552 & $-0.469 * *$ & -0.397 \\
\hline & $(0.0809)$ & $(0.0843)$ & $(0.162)$ & $(0.252)$ \\
\hline \multirow[t]{2}{*}{ Have any price regulation } & $0.176 * * *$ & $0.193 * * *$ & $0.113 * *$ & $0.121 * *$ \\
\hline & $(0.0536)$ & $(0.0576)$ & $(0.0435)$ & $(0.0418)$ \\
\hline \multirow[t]{2}{*}{ Chain pharmacy } & 0.0988 & -0.592 & 0.161 & -0.625 \\
\hline & $(0.117)$ & $(0.571)$ & $(0.125)$ & $(0.570)$ \\
\hline \multirow[t]{2}{*}{ Chain $*$ avg literacy rate } & & 0.514 & & 0.634 \\
\hline & & $(0.735)$ & & $(0.788)$ \\
\hline \multirow[t]{2}{*}{ Chain $*$ locally registered } & & $0.447^{*}$ & & $0.430 *$ \\
\hline & & $(0.223)$ & & $(0.245)$ \\
\hline \multirow{2}{*}{$\begin{array}{l}\text { Pharmacy assessed good } \\
\text { by shopper }\end{array}$} & 0.0605 & 0.0474 & 0.0643 & 0.0500 \\
\hline & $(0.0674)$ & $(0.0707)$ & $(0.0750)$ & $(0.0774)$ \\
\hline \multirow[t]{2}{*}{ Import } & -0.0253 & 0.0136 & -0.0249 & -0.00269 \\
\hline & $(0.0495)$ & $(0.0583)$ & $(0.0666)$ & $(0.0714)$ \\
\hline \multirow[t]{2}{*}{ Made in India } & 0.0204 & -0.0116 & 0.0699 & 0.0420 \\
\hline & $(0.101)$ & $(0.111)$ & $(0.109)$ & $(0.122)$ \\
\hline \multirow[t]{2}{*}{ Made in China } & -0.0936 & -0.143 & -0.0607 & -0.102 \\
\hline & $(0.0909)$ & $(0.0991)$ & $(0.109)$ & $(0.121)$ \\
\hline \multirow[t]{2}{*}{ Made in Europe/USA } & -0.0425 & -0.0386 & 0.0318 & 0.0408 \\
\hline & $(0.129)$ & $(0.119)$ & $(0.146)$ & $(0.152)$ \\
\hline \multirow[t]{2}{*}{ Purchased before 2012} & -0.126 & $-0.145^{* *}$ & -0.108 & $-0.125^{*}$ \\
\hline & $(0.0765)$ & $(0.0638)$ & $(0.0756)$ & $(0.0617)$ \\
\hline \multirow[t]{2}{*}{ City GDP per capita } & 0.00284 & 0.00202 & & \\
\hline & $(0.00736)$ & $(0.00758)$ & & \\
\hline \multirow[t]{2}{*}{ Avg adult literacy rate } & 0.156 & 0.101 & & \\
\hline & $(0.129)$ & $(0.153)$ & & \\
\hline \multirow[t]{2}{*}{ Purchased in Africa } & $0.365 * *$ & 0.230 & & \\
\hline & $(0.150)$ & $(0.162)$ & & \\
\hline \multirow[t]{2}{*}{ Purchased in Asia } & $0.270 * *$ & 0.172 & & \\
\hline & $(0.124)$ & $(0.131)$ & & \\
\hline Country FE & No & No & Yes & Yes \\
\hline Observations & 142 & 142 & 142 & 142 \\
\hline R-squared & 0.521 & 0.545 & 0.585 & 0.603 \\
\hline
\end{tabular}

Robust standard errors in parentheses, errors clustered by purchase country.

$* * * \mathrm{p}<0.01, * * \mathrm{p}<0.05, * \mathrm{p}<0.1$. 